\title{
Spectroscopic Characteristics of Highly Selective Manganese Catalysis in Acqueous Polyurethane Systems
}

\author{
Suzana Cakic ${ }^{1}$, Caslav Lacnjevac ${ }^{2, *}$, Goran Nikolic ${ }^{1}$, Jakov Stamenkovic ${ }^{1}$, Milos B. Rajkovic ${ }^{2}$, \\ Miladin Gligoric ${ }^{3}$ and Miroljub Barac ${ }^{2}$ \\ ${ }^{1}$ Faculty of Technology, 16000 Leskovac, Bul. oslobodenja 124, Serbia; \\ E-mails: suzana_cakic@yahoo.com (Suzana Cakic),goranchem_yu@yahoo.com (Goran Nikolić), \\ jakov.stamenkovic@le.sbb.co.yu (Jakov Stamenkovic) \\ ${ }^{2}$ Faculty of Agriculture, 11080 Belgrade-Zemun, St. Nemanjina 6, Serbia; \\ E-mails: ukilaki@eunet.yu (Caslav Lacnjevac), rajmi@agrifaculty.bg.ac.yu (Milos B. Rajkovic), \\ baracm@agrifaculty.bg.ac.yu (Miroljub Barac) \\ ${ }^{3}$ Faculty of Technology, 56000 Zvornik, Karakaj bb, Srpska Republic, \\ E-mail: lcaja@agrifaculty.bg.ac.yu (Miladin Gligoric) \\ *Author to whom correspondence should be addressed; E-mail: lcaja@agrifaculty.bg.ac.yu or \\ ukilaki@eunet.yu
}

Received: 25 September 2006 / Accepted: 12 November 2006 / Published: 20 November 2006

\begin{abstract}
The latest investigations on producing more efficient catalytic aqueous polyurethane systems are in the domain of metal complexes with mixed ligands. In our previous research works, the high selectivity for the isocyanate-hydroxyl reaction in aqueous polyurethane systems has been shown by the manganese(III) mixed-ligand complexes. The two new complexes have been prepared with two acetylacetonate (acac) ligands and one maleate ligand and its hydroxylamine derivative of the general formula $\left[\mathrm{Mn}\left(\mathrm{C}_{5} \mathrm{H}_{7} \mathrm{O}_{2}\right)_{2} \mathrm{~L}\right]$. Their structures have been established by using the fundamental analyses, the FTIR and UV/VIS spectroscopic methods, as well as the magnetic measurements. In order to explain the different selectivity of the manganese(III) mixed-ligand complexes, the UV and ESR spectroscopy have been employed to determine the kinetics of the complexes' decomposition. The thermal stability of the complexes has been determined by way of the dynamic TG method at the heating rate of $5^{\circ} \mathrm{C} \cdot \mathrm{min}^{-1}$ and at the temperature ranged 20$550^{\circ} \mathrm{C}$. It suggests the decomposition of the
\end{abstract}


complexes by loss of acid ligand. The main factor in the selective catalysis control in the aqueous polyurethane systems is the nature of the acid ligands and their impact on the manganese(II)/manganese(III) equilibrium.

Keywords: catalyst's selectivity, manganese(III) complexes, fourier transform infrared spectra (FTIR), electronic spectra (UV), electron spin resonance (ESR).

\section{Introduction}

The main problem in formulating the aqueous polyurethane systems is the isocyanate-water side reaction, which can lead to gassing/foaming, pinholes, loss of isocyanate functionality, low gloss, and a reduced pot life. The formation of carbon dioxide also lowers the $\mathrm{pH}$ of the emulsion or dispersion, which can reduce the stability of the aqueous formulations [1,2]. A new approach in monitoring the water side reaction is the use of catalysts which selectively catalyze the isocyanate-polyol reaction but not the isocyanate-water reaction [3] (Figure 1).

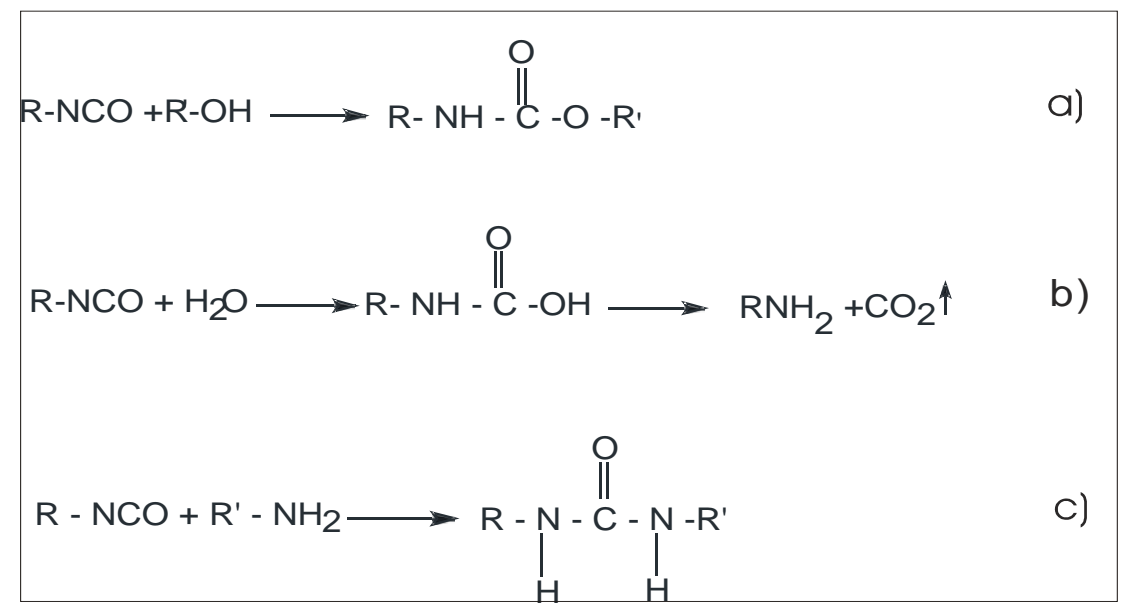

Figure 1. Isocyanate reactions with alcohol (a) and with water (b,c).

In the previous works of Blank [4], the selectivity of different compounds compared to model compounds has been investigated. Butyl isocyanate and 2-ethyl-1-hexanol have been chosen as model compounds due to their similarity to the aliphatic polyisocyanate and hydroxyl resins, as well as because of the simplicity of their FTIR spectra. The reaction product ratio, urethane/urea, has been used as a measure of the relative selectivity. In our previous works [5], the high selectivity is showed by the manganese(III) mixed-ligand complexes with two acetylacetone ligands and one maleate ligand and its hydroxylamine derivative. The catalytic ability of a complex is determined by its composition and it depends on the nature of a ligand. It gives a possibility to change the complex structure and its selective catalytic activity by changing the ligands [6]. The synergistic action of the complex Mn(III)acetylacetone with acid leads to the ligands exchange and to the formation of mixed Mn(III)-diacetyl acetonecarboxylate helate [7]. The replacement of the acetylacetone with the carboxylate ligand increases the helate activity in the catalytic reaction. Catalyses usually go over splitting ligand and oxidation of $\mathrm{Mn}(\mathrm{II})$ into $\mathrm{Mn}(\mathrm{III})$. The increased activity of the complex is connected with the 
helate electronic structure change [8,9,10]. In order to explain the lower selectivity of Mn(III)diacetylacetonehydroxylaminmaleate in comparison to $\mathrm{Mn}$ (III)-diacetylacetonemaleate, as well as the different impact of inductive time on film hardness [11,12], the UV and ESR spectroscopy have been used to determine the kinetics of the complex decomposition of the manganese(III) mixed-ligand.

\section{Experimental}

\section{Instrumental measurements}

The carbon, hydrogen and nitrogen analyses have been performed using a CHN 24000 PerkinElmer analyzer. The manganese content has been determined by the spectrophotometric method, at $525 \mathrm{~nm}$. The Fourier-transform infrared (FTIR) spectra were recorded using a Michaelson Bomem MB-series spectrophotometer and the $\mathrm{KBr}$ pellet $(1 \mathrm{mg} / 100 \mathrm{mg}$ ) technique. Magnetic susceptibilities have been determined at room temperature employing the MSB-MKI magnetic susceptibility balance (Sherwood Scientific Ltd., Cambridge, England). The electronic spectra (UV/VIS) have been recorded on a Varian Cary-100 spectrophotometer using $10^{-4}$ moldm $^{-3}$ solutions in ethanol in quartz cuvettes. The electron spin resonance (ESR) measurements of water samples have been recorded at $20^{\circ} \mathrm{C}$ on the X-band microwave frequency on a Bruker 300E spectrometer utilizing $25.0 \mathrm{kHz}$ magnetic field modulation. The TGA/DTA curves of the complexes have been studied in the air atmosphere at the heating rate of $10^{\circ} \mathrm{C} \cdot \mathrm{min}^{-1}$, at the temperatures ranged $20-550^{\circ} \mathrm{C}$, using the Bomen $\mathrm{TGS}+$ Thermogravimetric system.

\section{Synthesis of the complexes}

All the used chemicals have been of the p.a. grade purity. The starting complex $\left[\mathrm{Mn}\left(\mathrm{C}_{5} \mathrm{H}_{7} \mathrm{O}_{2}\right)_{3}\right]$ has been obtained from commercial sources and has been utilized without further purification.

Synthesis of Mn(III) diacetylacetonemaleate (I). Maleic anhydride and methanol (1:1) have been refluxed for $120 \mathrm{~min}$. The [ $\left.\mathrm{Mn}\left(\mathrm{C}_{5} \mathrm{H}_{7} \mathrm{O}_{2}\right)_{3}\right]$ has been dissolved in benzene. The reaction mixture has been cooled and the equimolar amounts of $\left[\mathrm{Mn}\left(\mathrm{C}_{5} \mathrm{H}_{7} \mathrm{O}_{2}\right)_{3}\right]$ and monomethylmaleate have been mixed. The mixture has been held at $10-25^{\circ} \mathrm{C}$ for about $10-20 \mathrm{~min}$. The dark-green product (insoluble in benzene) has been filtered under vacuum, washed with solvent and dried at room temperature, the yield being $90 \%$.

Synthesis of Mn(III) diacetylacetonehydroxylaminmaleate (II). In order to synthetize these complexes, the maleic anhydride and methanol (1:1) have been refluxed for $120 \mathrm{~min}$, and hydroxylamine hydrochloride in ethanol $\left(0.5 \mathrm{~mol} \mathrm{dm}^{-3}\right)$ has been added in an equimolar amount, the refluxing lasting about $15 \mathrm{~min}$. To cool the redistilled solution, the Mn(III)-acetylacetone complex (previously dissolved in a minimal volume of benzene) has been added. The green product has been filtered under vacuum, washed with the solvent and dried at room temperature, the yield being $80 \%$.

\section{Results and Discussion}

The results of the microanalysis of carbon, hydrogen and nitrogen in the investigated compounds are given in Table 1 . The complexes have been synthesized applying the Mn(III)-acetylacetone and the 
acid ligand in the 1:1 mole ratio. The results in Table 1 indicate the replacement of the acetylacetone ligand by the corresponding acid ligand. The complexes are soluble in water, tetrahydrofurane, propylene glycol, metoxypropylacetate and other polar solvents.

Table 1. Data of the basic analysis of the investigated compounds $\left(\mathrm{L}^{1}=-\mathrm{OCO}-\mathrm{CH}=\mathrm{CH}-\mathrm{COOH}, \mathrm{L}^{2}=-\mathrm{OCO}-\mathrm{CH}=\mathrm{CH}-\mathrm{CONHOH}\right)$.

\begin{tabular}{|c|c|c|c|c|c|c|c|c|c|c|c|}
\hline \multirow[t]{2}{*}{ Compounds } & \multirow{2}{*}{$\begin{array}{l}\text { Molecular } \\
\text { Formula }\end{array}$} & \multirow{2}{*}{$\begin{array}{l}\text { Yield } \\
\text { (in \%) }\end{array}$} & \multirow[t]{2}{*}{ Colour } & \multicolumn{2}{|c|}{$\begin{array}{c}\text { Carbon } \\
\text { (in \%) }\end{array}$} & \multicolumn{2}{|c|}{$\begin{array}{l}\text { Hydrogen } \\
\text { (in \%) }\end{array}$} & \multicolumn{2}{|c|}{$\begin{array}{l}\text { Nitrogen } \\
\text { (in \%) }\end{array}$} & \multicolumn{2}{|c|}{$\begin{array}{c}\text { Manganese } \\
\text { (in \%) }\end{array}$} \\
\hline & & & & found & calcd & found & calcd & found & calcd & found & calcd \\
\hline I & {$\left[\mathrm{Mn}\left(\mathrm{C}_{5} \mathrm{H}_{7} \mathrm{O}_{2}\right)_{2} \mathrm{~L}^{1}\right]$} & 90 & $\begin{array}{l}\text { dark- } \\
\text { green }\end{array}$ & 44.33 & 45.61 & 4.57 & 4.62 & - & - & 15.3 & 14.9 \\
\hline II & {$\left[\mathrm{Mn}\left(\mathrm{C}_{5} \mathrm{H}_{7} \mathrm{O}_{2}\right)_{2} \mathrm{~L}^{2}\right]$} & 80 & green & 42.51 & 43.82 & 4.59 & 4.70 & 3.51 & 3.65 & 13.6 & 14.3 \\
\hline
\end{tabular}

\section{Infrared spectra}

The band at $\sim 3564 \mathrm{~cm}^{-1}$ (-OH stretching vibration) indicate the acetylacetone ligand's replacement with the maleic acid in the compound (I). The bands at $1708 \mathrm{~cm}^{-1}$ and $\sim 1338 \mathrm{~cm}^{-1}$ have been assigned to the asymmetric and symmetric stretching vibrations of the COOH-group [7]. The two bands of the ionized carboxylic group have been detected, too: the first at $1615 \mathrm{~cm}^{-1}$ of the asymmetric vibrations and the second at $1458 \mathrm{~cm}^{-1}$ from the symmetric vibrations (Figure 1).

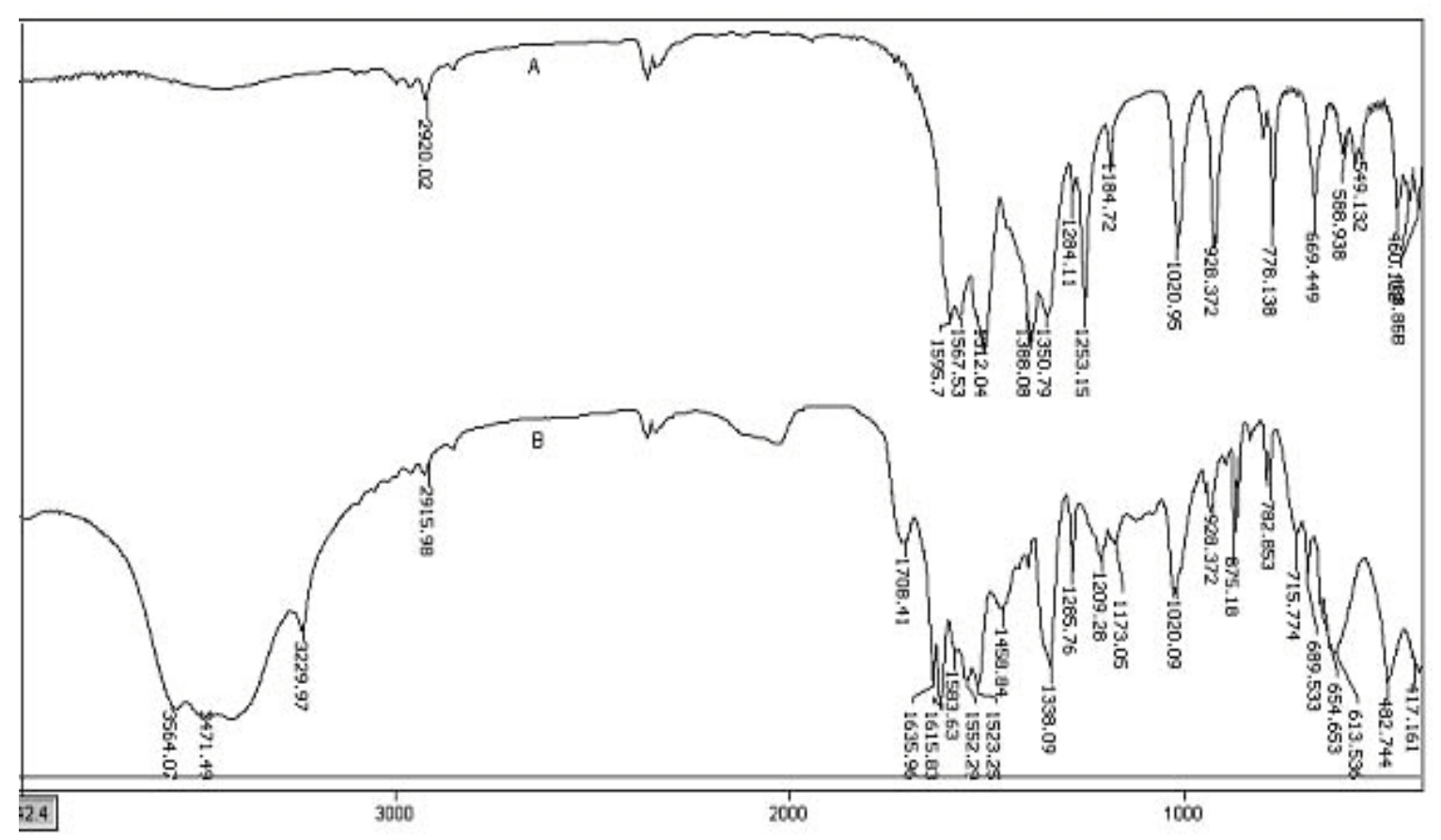

Figure 1. Comparative FTIR spectra: A) the complex of Mn(III)-acetylacetone, B) the complex of $\mathrm{Mn}(\mathrm{III})$-diacetylacetonemaleate. 
The complex with the hydroxylamine derivative of the maleic acid has showed vibrations only of the $v_{\mathrm{as}}\left(\mathrm{COO}^{-}\right)$and $v_{\mathrm{s}}\left(\mathrm{COO}^{-}\right)$at $1595 \mathrm{~cm}^{-1}$ and $1407 \mathrm{~cm}^{-1}$.

The bands at 417, 482,613, 654, $689 \mathrm{~cm}^{-1}$, assigned to Mn-O vibrations, as well as the bands at 928 and $1020 \mathrm{~cm}^{-1}$ show that the $\mathrm{Mn}(\mathrm{III})$ is bonded to two acetylacetone ligands. The band at $1312 \mathrm{~cm}^{-1}$ attributed to the coupling of the $v(\mathrm{C}-\mathrm{N})$ and $\delta(\mathrm{N}-\mathrm{H})$ vibrations and $\delta(\mathrm{N}-\mathrm{H})$ deformation band at 717 $\mathrm{cm}^{-1}$ confirm this suggestion (Table 2 ).

Table 2. The FTIR spectral data of the compounds [frequency $\left(\mathrm{cm}^{-1}\right)$ ].

\begin{tabular}{|c|c|c|c|}
\hline$\left[\mathrm{Mn}\left(\mathrm{C}_{5} \mathbf{H}_{7} \mathrm{O}_{2}\right)_{3}\right]$ & {$\left[\mathbf{M n}\left(\mathbf{C}_{5} \mathbf{H}_{7} \mathbf{O}_{2}\right)_{2} \mathbf{L}^{1}\right]$} & {$\left[\mathbf{M n}\left(\mathbf{C}_{5} \mathbf{H}_{7} \mathbf{O}_{2}\right)_{2} \mathbf{L}^{2}\right]$} & Assigment of bands ${ }^{\text {a }}$ \\
\hline $430 \mathrm{~m}$ & $417 \mathrm{~m}$ & $425 \mathrm{~m}$ & $v(\mathrm{Mn}-\mathrm{O}), \delta(\mathrm{Mn}-\mathrm{O}=\mathrm{C})$ \\
\hline $460 \mathrm{~m}$ & $482 \mathrm{~m}$ & $487 \mathrm{~m}$ & $v(\mathrm{Mn}-\mathrm{O}), v\left(\mathrm{C}-\mathrm{CH}_{3}\right), v(\mathrm{C}=\mathrm{C})$ \\
\hline $550 \mathrm{~m}$ & $613 \mathrm{~m}$ & $575 \mathrm{~m}^{\mathrm{b}}$ & $\pi_{r i n g}+v(\mathrm{Mn}-\mathrm{O})$ \\
\hline $588 \mathrm{~s}$ & $654 \mathrm{~s}$ & $633 \mathrm{~m}$ & $\begin{array}{c}v(\mathrm{Mn}-\mathrm{O}) \\
\delta\left(\mathrm{Mn}-\mathrm{O}=\mathrm{C}, \mathrm{CH}_{3}-\mathrm{C}=\mathrm{O}\right)\end{array}$ \\
\hline \multirow[t]{2}{*}{$669 \mathrm{~ms}$} & $689 \mathrm{~m}$ & $689 \mathrm{~m}$ & $\begin{array}{c}v\left(\mathrm{C}-\mathrm{CH}_{3}\right), v(\mathrm{Mn}-\mathrm{O}) \\
\delta\left(\mathrm{O}=\mathrm{C}-\mathrm{CH}_{3}\right)\end{array}$ \\
\hline & & $771 \mathrm{~m}$ & $\gamma(\mathrm{N}-\mathrm{H})$ \\
\hline \multirow[t]{2}{*}{$778 \mathrm{~s}$} & $782 \mathrm{~s}$ & $778 \mathrm{w}^{\mathrm{c}}$ & $\pi(\mathrm{C}-\mathrm{H})$ \\
\hline & $875 \mathrm{~m}$ & $876 \mathrm{~m}$ & $\delta(\mathrm{COO})$ \\
\hline $928 \mathrm{~s}$ & $928 \mathrm{~m}$ & $927 \mathrm{~m}$ & $v\left(\mathrm{C}-\mathrm{CH}_{3}\right)$ \\
\hline $1020 \mathrm{~s}$ & $1020 \mathrm{~s}$ & $1023 \mathrm{~s}$ & $\gamma\left(\mathrm{CH}_{3}\right)$ \\
\hline $1185 \mathrm{w}$ & $1173 \mathrm{w}$ & $1180 \mathrm{w}$ & $\delta(\mathrm{C}=\mathrm{CH})$ \\
\hline \multirow[t]{3}{*}{$1253 \mathrm{~s}$} & $1285 \mathrm{~s}$ & $1281 \mathrm{~m}$ & $v(\mathrm{C}=\mathrm{C}), v\left(\mathrm{C}-\mathrm{CH}_{3}\right)$ \\
\hline & & $1312 \mathrm{~m}$ & $v(\mathrm{C}-\mathrm{N}), \delta(\mathrm{N}-\mathrm{H})$ \\
\hline & $1338 \mathrm{~s}$ & & $\left.v_{s} \mathrm{COOH}\right)$ \\
\hline $1350 \mathrm{~s}$ & & $1361 \mathrm{~s}$ & $\delta\left(\mathrm{CH}_{3}\right)$ \\
\hline \multirow[t]{2}{*}{$1388 \mathrm{~s}$} & $1388 \mathrm{w}$ & & $\delta\left(\mathrm{CH}_{3}\right)$ \\
\hline & $1458 \mathrm{~m}$ & $\begin{array}{l}1407 \\
1462 \mathrm{~m}\end{array}$ & $\begin{array}{c}v_{\mathrm{s}}(\mathrm{COO}) \\
\delta(=\mathrm{CH})\end{array}$ \\
\hline $1512 \mathrm{~s}$ & $1523 \mathrm{~s}$ & $1514 \mathrm{~s}$ & $v(\mathrm{C}=\mathrm{C}), \delta(\mathrm{C}=\mathrm{CH})$ \\
\hline $1567 \mathrm{~s}$ & $1552 \mathrm{~s}$ & $1551 \mathrm{~s}$ & $v(\mathrm{C}=\mathrm{C}), \delta(\mathrm{C}=\mathrm{CH})$ \\
\hline \multirow[t]{4}{*}{$1595 \mathrm{~s}$} & $1615 \mathrm{~s}$ & $1595 \mathrm{~s}$ & $v_{a s}(\mathrm{COO})$ \\
\hline & $1635 \mathrm{~s}$ & & $v(\mathrm{C}=\mathrm{C})$ \\
\hline & & $1651 \mathrm{~m}$ & $v(\mathrm{C}=\mathrm{O})$ \\
\hline & $1708 \mathrm{~m}$ & & $v_{a s}(\mathrm{COOH})$ \\
\hline \multirow[t]{4}{*}{$2920 \mathrm{w}$} & $2915 \mathrm{w}$ & $2920 \mathrm{w}$ & $v(\mathrm{C}-\mathrm{H})$ \\
\hline & $3229 \mathrm{~m}$ & $3213 \mathrm{~m}$ & $v(=\mathrm{CH})$ \\
\hline & & $3559 \mathrm{~m}$ & $v(\mathrm{~N}-\mathrm{H})$ \\
\hline & $3564 \mathrm{~s}$ & $3400 \mathrm{~s}$ & $v(\mathrm{O}-\mathrm{H})$ \\
\hline
\end{tabular}

Notes: ${ }^{a}$ Relative intesity: s-strong, m-medium, w-weak and ${ }^{\mathrm{b}} \pi_{\text {ring }}$, ring deformation out-of-plane that includes torsions $\tau \mathrm{O}-\mathrm{C}-\mathrm{C}-\mathrm{C}, \tau \mathrm{O}-\mathrm{C}-\mathrm{C}-\mathrm{H}, \tau \mathrm{CH}_{3}-\mathrm{C}-\mathrm{C}-\mathrm{H} ;{ }^{c} \pi(\mathrm{C}-\mathrm{H}), \mathrm{C}-\mathrm{C}-\mathrm{C}-\mathrm{H}$ out-of-plane vibration.

The two major bands have appeared in the complex (II): NH stretching vibrations at $\sim 3559 \mathrm{~cm}^{-1}$ and the band attributed to the vibration of the carbonyl $\mathrm{C}=\mathrm{O}$ group $\left(1651 \mathrm{~cm}^{-1}\right)$ indicating the replacement of the acetylacetone ligand by the hydroxylaminmaleate ligand [7].

The bands at 417, 482,613, 654, $689 \mathrm{~cm}^{-1}$, assigned to Mn-O vibrations, as well as the bands at 927 and $1023 \mathrm{~cm}^{-1}$ show that $\mathrm{Mn}(\mathrm{III})$ is coordinated to two acetylacetone ligands (Figure 2).

The main frequencies and their assignments are presented in Table 2. 
Thus, the data (Table 2) from the infrared spectra provide the clear evidence that the ligands of the maleic acid and its hydroxylamine derivative are bonded with two acetylacetone ligands in the Mn(III) mixed-ligand complexes.

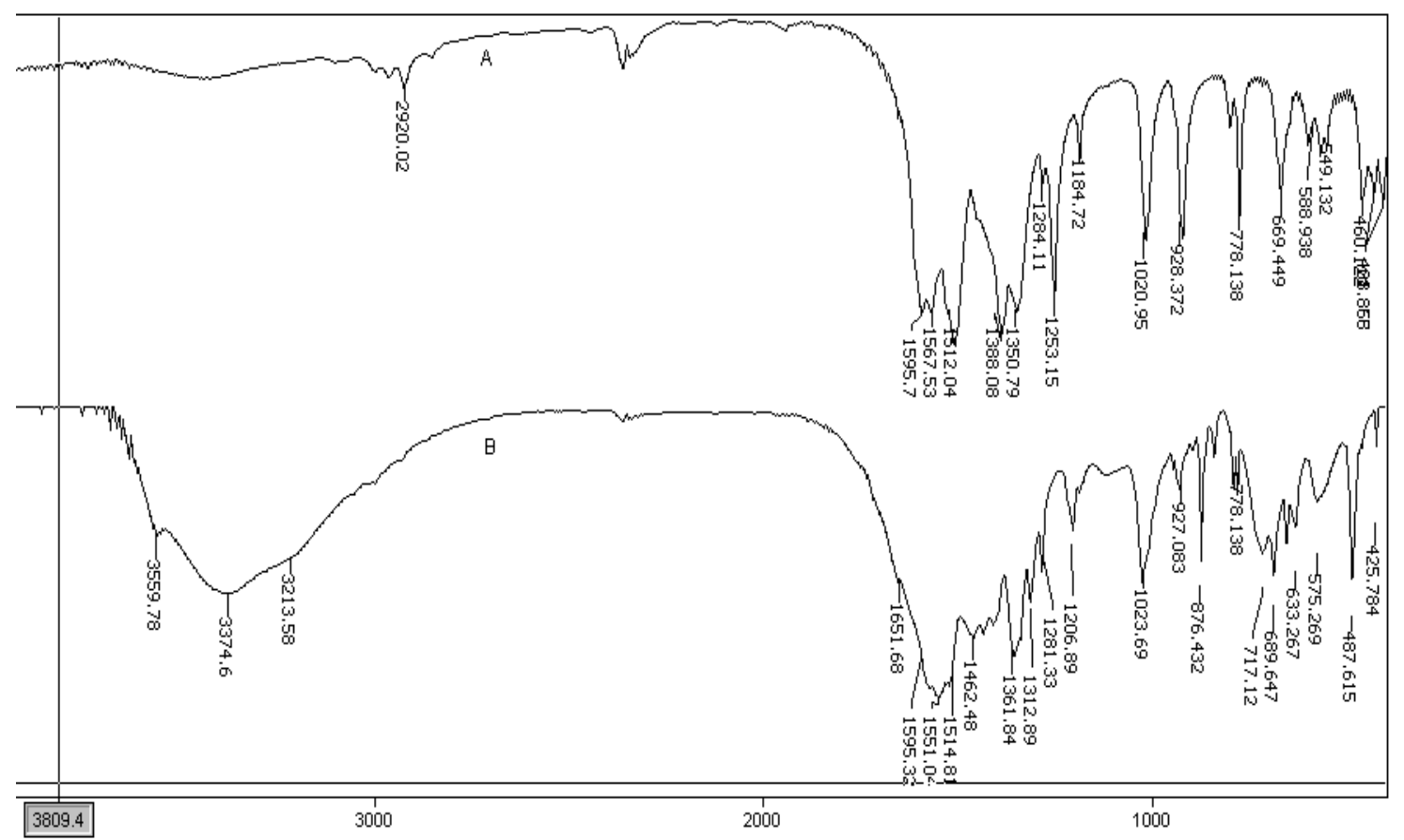

Figure 2. Comparative FTIR spectra:

A) the complex of Mn(III)-acetylacetone

B) the complex of Mn(III)-diacetylacetonehydroxylaminmaleate.

\section{Electronic spectra}

The spectral data and magnetic moments of the compounds are presented in Table 3. In the complex Mn(III)-acetylacetone [6], there are two absorption bands, assigned to $\pi \rightarrow \pi^{*}$ transitions and one apsorption band assigned to $\pi^{*} \rightarrow \mathrm{d}$ transition. These transitions have also been found in the spectra of the synthesized complexes, but they are shifted towards lower and higher frequencies, depending on the ligands structures.

Table 3. The electronic spectral data of the complexes recorded in ethanol [frequency $\left(\mathrm{cm}^{-1}\right) / \varepsilon_{\max }\left(\mathrm{mol}^{-1} \mathrm{dm}^{3} \mathrm{~cm}^{-1}\right)$ ].

\begin{tabular}{ccccccc}
\hline \multirow{2}{*}{ Complex } & $\boldsymbol{\mu}_{\text {eff }} / \boldsymbol{\mu}_{\mathbf{B}}$ & $\boldsymbol{\pi} \rightarrow \boldsymbol{\pi}^{*}$ & $\boldsymbol{\pi} \rightarrow \boldsymbol{\pi}^{*}$ & $\boldsymbol{v}\left(10^{4} \mathbf{c m}^{\mathbf{- 1}}\right) / \boldsymbol{\varepsilon}$ \\
\cline { 3 - 7 } $\boldsymbol{n n n y y y} \rightarrow \mathbf{d}$ & $\mathbf{d} \rightarrow \mathbf{d}^{*}$ & $\mathbf{d} \rightarrow \mathbf{d}^{*}$ \\
\hline$\left[\mathrm{Mn}\left(\mathrm{C}_{5} \mathrm{H}_{7} \mathrm{O}_{2}\right)_{3}\right]$ & 4.90 & $40.8 / 17500$ & $36.4 / 24000$ & $30.7 / 9500$ & $24.8 / 950$ & $17.5 / 100$ \\
{$\left[\mathrm{Mn}\left(\mathrm{C}_{5} \mathrm{H}_{7} \mathrm{O}_{2}\right)_{2} \mathrm{~L}^{1}\right]$} & 4.76 & $41.6 / 31000$ & $35.2 / 12000$ & $30.2 / 17500$ & $24.3 / 1000$ & $17.6 / 70$ \\
{$\left[\mathrm{Mn}\left(\mathrm{C}_{5} \mathrm{H}_{7} \mathrm{O}_{2}\right)_{2} \mathrm{~L}^{2}\right]$} & 4.81 & $42.0 / 22500$ & $35.9 / 14500$ & $30.3 / 11000$ & $24.8 / 1500$ & $17.5 / 170$ \\
\hline
\end{tabular}

In the VIS electronic absorption spectrum there are two absorption bands assigned to $\mathrm{d} \rightarrow \mathrm{d}^{*}$ transitions in the complexes (I, II). These bands could be attributed to a changed transfer transition, or even to the $d \rightarrow d^{*}$ transition. The color of the complexes is probably due to these transitions. The color 
of the transition metal complexes has originated from d-orbitals. It is known that a ligand splits dorbitals of the central ion into two groups. This splitting is weak and the excitation of an electron from $t_{2 g}$ to $e_{g}$ orbitals is always observed in the visible electronic absorption spectra.

\section{Magnetic properties}

An indication of the most probable stereochemistry of the synthesized manganese(III) complexes is given by its color and a magnetic moment. Namely, the black Mn(III)-acetylacetone complex usually has an octahedral configuration. The room temperature effective magnetic moments of the manganese(III) complexes with mixed ligands are in the range of 4.76-4.9 $\mu_{\mathrm{B}}$, which corresponds to four unpaired electrons typical of the $\mathrm{d}^{4}$ system.

It is supposed that in the mixed-ligand complexes the ligands have localized $\pi$-bonds and do not favor the electron-pairing. The Jahn-Teller effect, due to an unequal filling up of $t_{2 g}$ and $e_{g}$ orbitals, yields a distorted octahedral geometry in complexes. These complexes have a dark green to green colour [13].

The proposed structures of the complexes shown in Figure 3 are consistent with the related data [6].

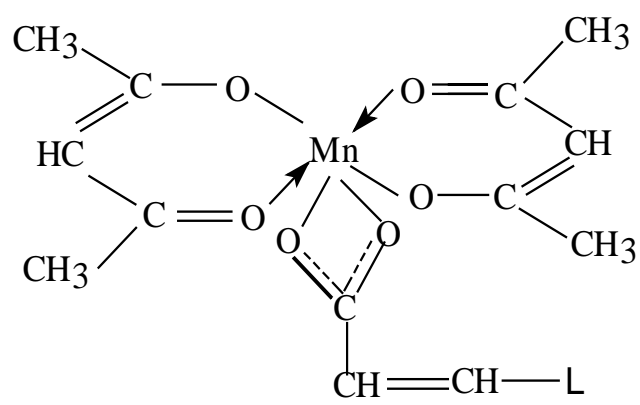

A

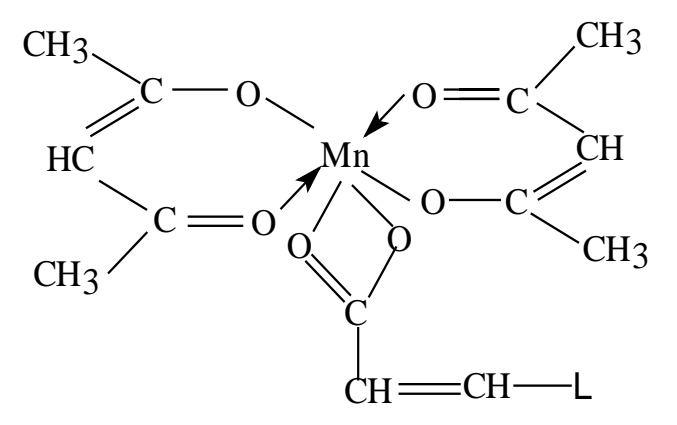

B

Figure 3. The proposed structure of the complexes with mixed ligands

$\mathrm{L}=-\mathrm{COOH}, \mathrm{Mn}(\mathrm{III})$-diacetylacetonemaleate

$\mathrm{L}=-\mathrm{CONHOH}, \mathrm{Mn}(\mathrm{III})$-diacetylacetonehydroxylaminmaleate.

\section{Decomposition of the complex with the mixed ligand}

In the complex $\mathrm{Mn}(\mathrm{III})$-diacetylacetonemaleate, there are two absorption bands at $240 \mathrm{~nm}$ and 280 $\mathrm{nm}$ assigned to the $\pi \rightarrow \pi^{*}$ transitions, and one absorption band at $325 \mathrm{~nm}$ assigned to the $\pi^{*} \rightarrow \mathrm{d}$ transitions. These bands have significant maximums and their overlapping is less than for Mn(III)acetylacetone, which is consistent with the already known data for the similar manganese(III) mixedligand complexes.

In the previous researches [14,15], the rate of the ligand exchange in Mn(III)-acetylacetone with the other (acid one) in the methanol solution has been investigated. The addition of $\mathrm{Mn}$ (II)-acetylacetone decreases the rate of ligands exchange, supposing the formation of the mixed complex $\mathrm{Mn}^{3+}\left(\mathrm{C}_{5} \mathrm{H}_{7} \mathrm{O}_{2}\right)_{\mathrm{x}}$ $\mathrm{Mn}^{2+}$ that does not undergo homolysis. Similar results are found for the $\mathrm{Cu}^{1+} \mathrm{Cu}^{2+}$ mixed complex [16]. 
As it is shown (Figure 4), the decomposition of the Mn(III)-diacetylacetonemaleate complex decreases in time with the intensity of the band at $240 \mathrm{~nm}$ due to the $\pi \rightarrow \pi^{*}$ transition in the ligand. It can also be seen, that the already mentioned band at $325 \mathrm{~nm}$, which is consistent with $\pi^{*} \rightarrow \mathrm{d}$, also decreases in intensity during the same period. In contrast to this, the intensity of the band at $280 \mathrm{~nm}$ increases.

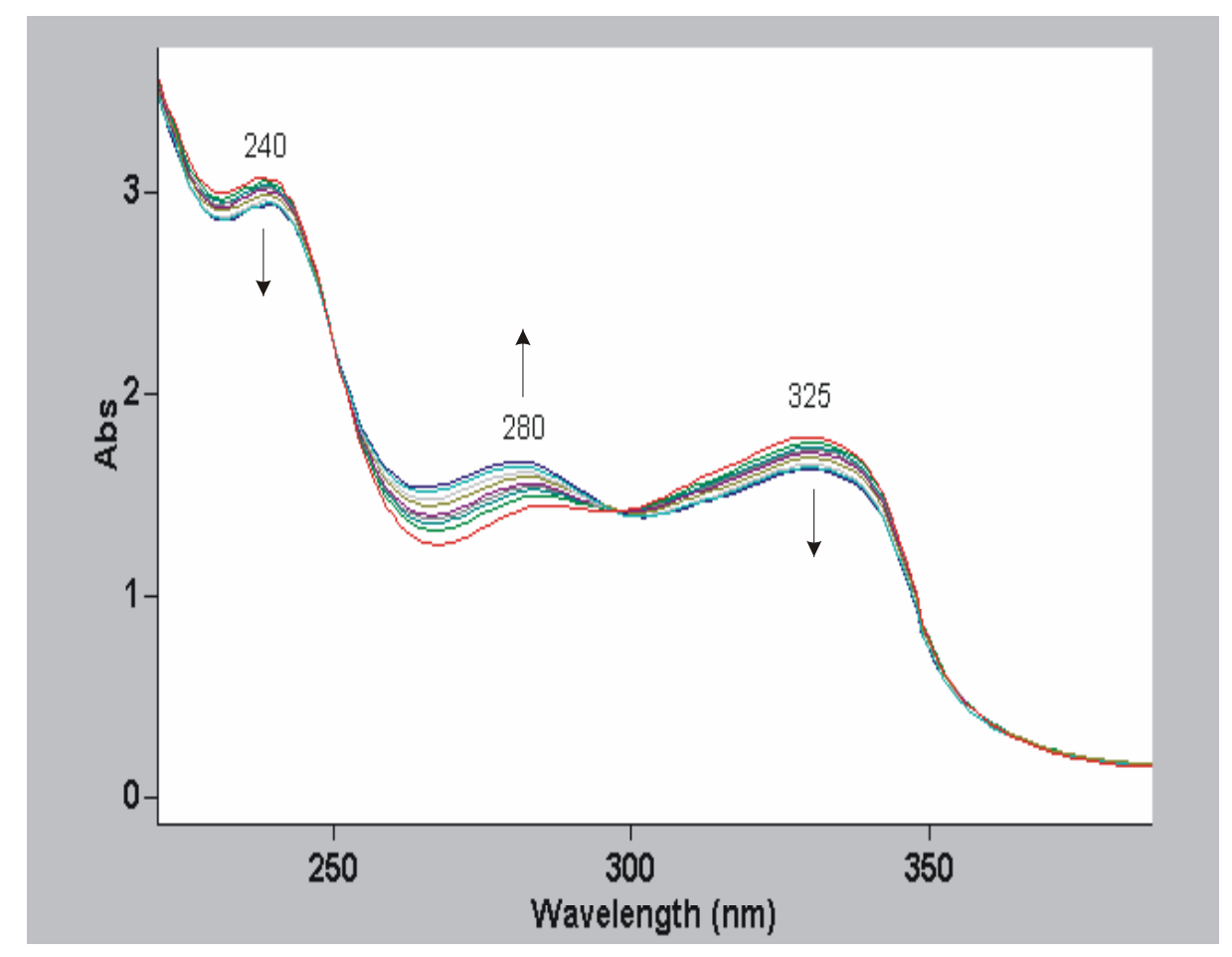

Figure 4. The UV spectra of the decomposition of the complex of Mn(III)-diacetylacetonemaleate in ethanol with time (30 min.).

The parallel changing of the band intensity at 280 and $325 \mathrm{~nm}$ for the Mn(III)-acetylacetone and $\mathrm{Mn}(\mathrm{III})$-diacetylacetonemaleate complexes, shows that the reduction is faster with $\mathrm{Mn}(\mathrm{III})$ acetylacetone, reaching the balance in $10 \mathrm{~min}$. It suggests that the once established $\mathrm{Mn}^{3+} / \mathrm{Mn}^{2+}$ balance does not permit further transition $\mathrm{Mn}^{3+}$ in $\mathrm{Mn}^{2+}$.

The decomposition of the complex with the mixed ligands is slower and the balance is established after $30 \mathrm{~min}$. The spectra have been recorded periodically every $3 \mathrm{~min}$. In the complex Mn(III)diacetylacetonemaleate, the balance has been established after 9 times (27 min), but there has been no change in the UV spectra of Mn(III)-acetylacetone after 9 min (Figure 5). 


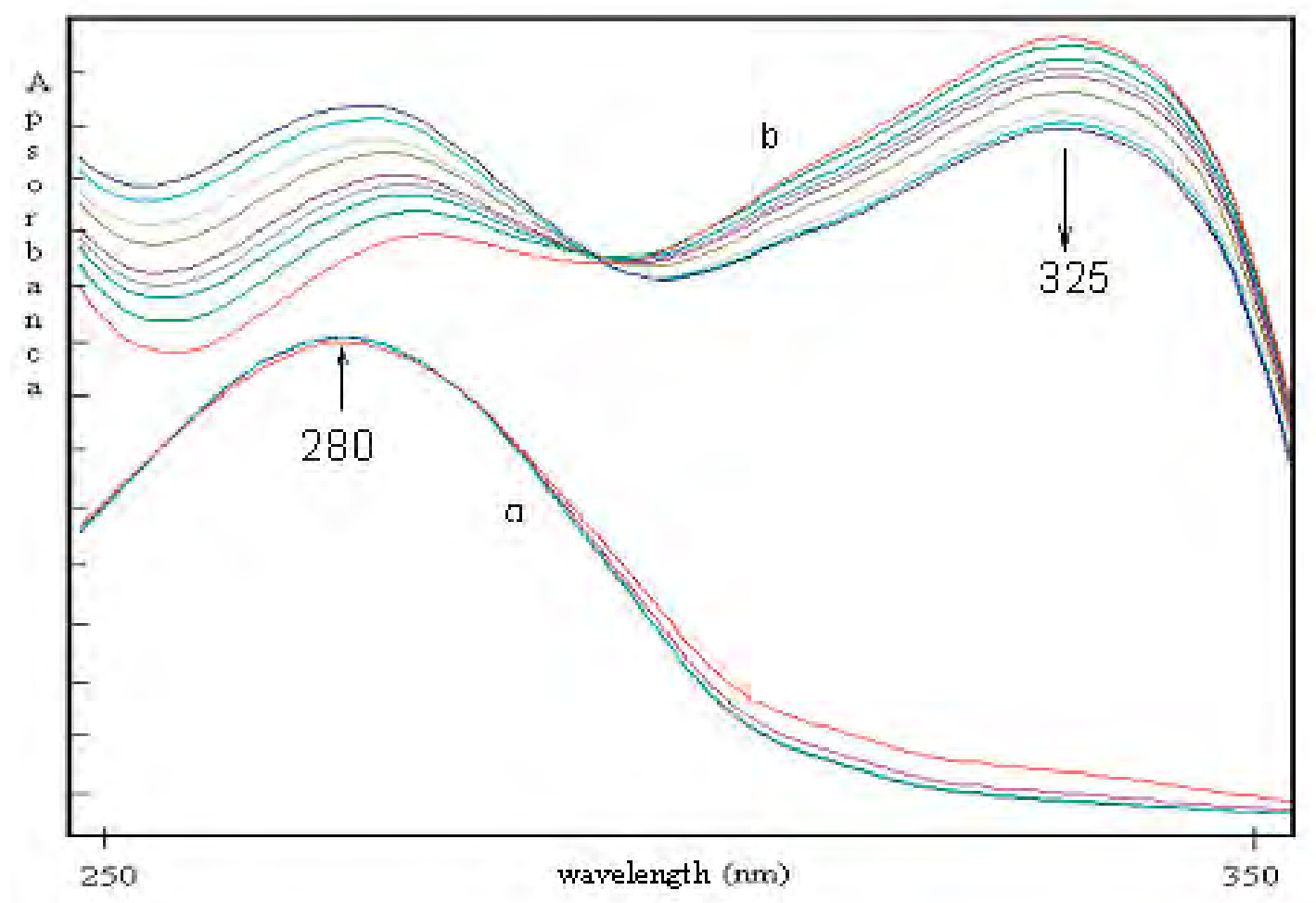

Figure 5. The comparison of the UV spectra

a) of $\mathrm{Mn}(\mathrm{III})$-acetylacetone and

b) of $\mathrm{Mn}(\mathrm{III})$-diacetylacetonemaleate in ethanol with respect to time.

In the $\mathrm{Mn}(\mathrm{III})$-diacetylacetonehydroxylaminmaleate, the balance $\mathrm{Mn}^{3+} / \mathrm{Mn}^{2+}$ is established very fast, in $15 \mathrm{~min}$, and does not permit further transition manganese(III) in manganese(II). The concentration of the acid ligand in the solution is somewhat less, compared to other complexes where the balance is established a little bit slowlier (Figure 6).

The ESR spectroscopy is used to observe the concentration of $\mathrm{Mn}^{2+}$, obtained as a product of the $\mathrm{Mn}^{3+}$ reduction [17]. It is shown that once the balance has been established in the solution, the coordinated acid ligand (hydroxylamine derivative of the maleic acid) decreases the effect of the positive charge of the $\mathrm{Mn}^{3+}$ ion making the reduction difficult. When the balance is established in the solution, the concentration of the $\mathrm{Mn}^{2+}$ ion is higher in the complex with the maleic acid ligand (Figure 7a), than in the complex with the ligand consisting of the hydroxylamine derivative of the maleic acid (Figure 7b). 


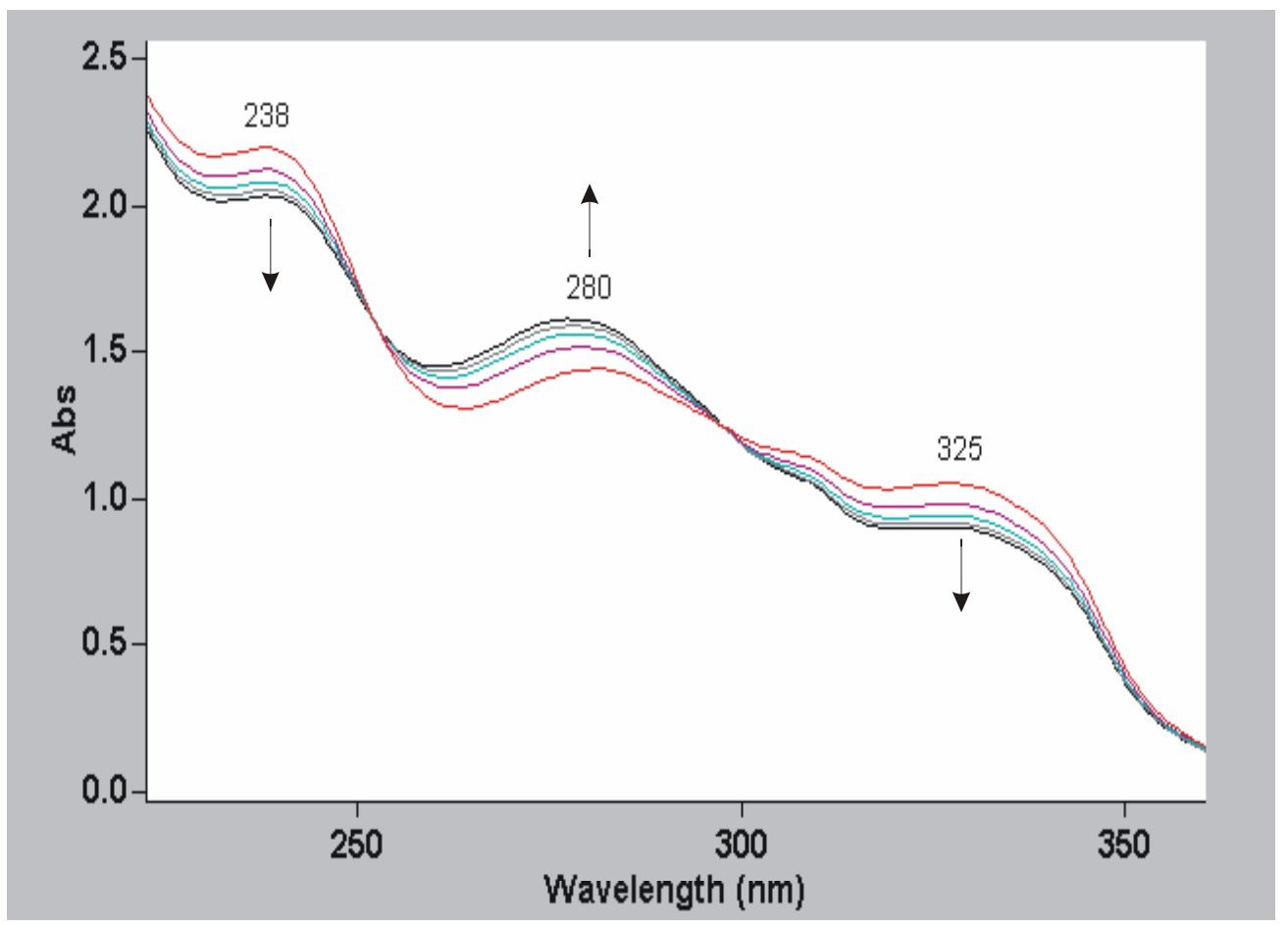

Figure 6. The UV spectra of the decomposition of the complex of Mn(III)diacetylacetonehydroxylaminmaleate in ethanol with respect to time (15 min).

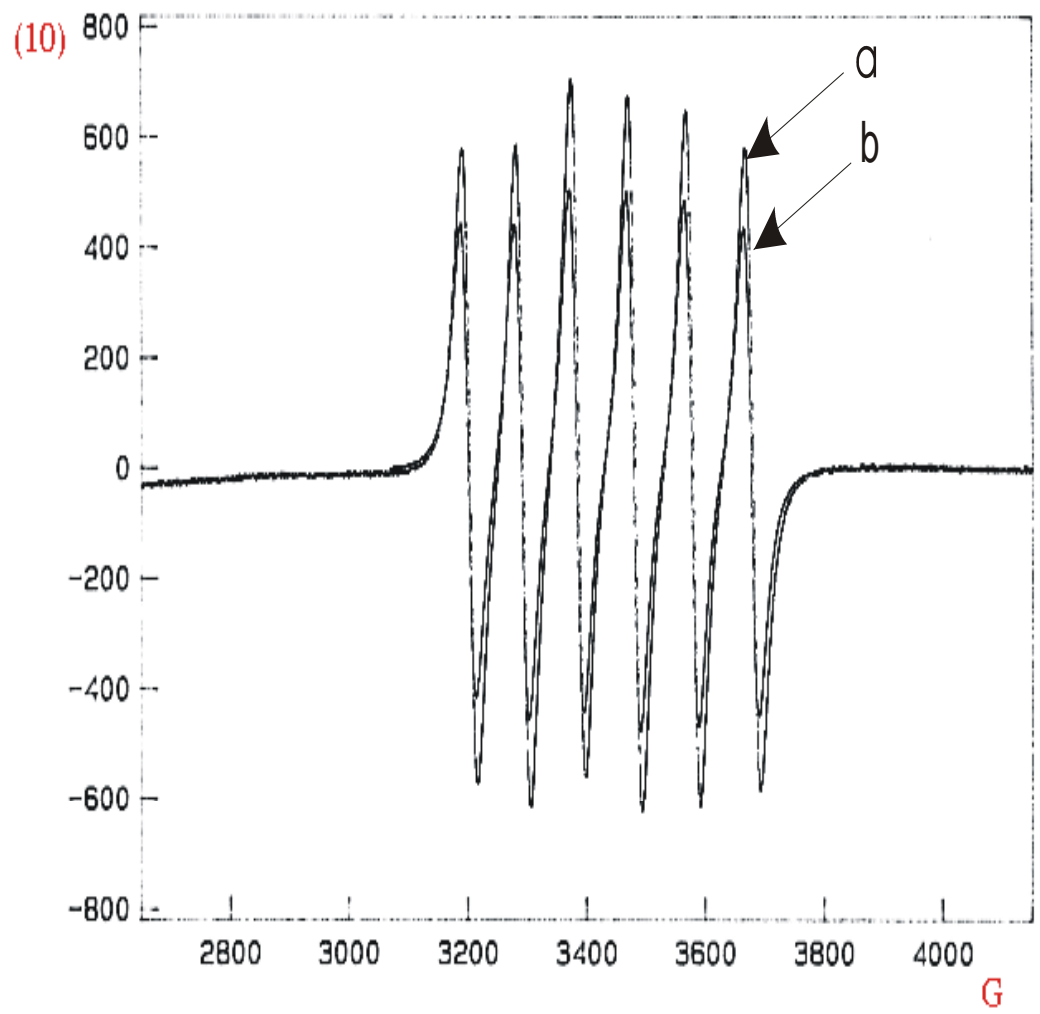

Figure 7. The comparison of the ESR spectra after the balance has been established of $\mathrm{Mn}^{3+} / \mathrm{Mn}^{2+}$ a) of $\mathrm{Mn}$ (III)-diacetylacetonemaleate, and b) of Mn(III)-diacetylacetonehydroxylaminmaleate. 
The reduction of the $\mathrm{pH}$ of water, as a result of the dissolution of the manganese(III) complex, confirms the removal of the acid ligand out of the complex. However, the removal of the acetyl acetone ligand will increase the $\mathrm{pH}$ since the ligand receives a proton from the solution and transforms into acetylacetone [16].

The thermal analysis of the $\mathrm{Mn}(\mathrm{III})$-acetylacetone complex suggests that the acetyl acetone ligand is released. The weight loss of $28 \%$ at $160^{\circ} \mathrm{C}$, is in accordance with splitting the acetylacetone ligand. This is in good relation with the theoretical weight loss of $31.3 \%$. The TG and DTG curves in Mn(III)diacetylacetonemaleate show the first weight loss at $160^{\circ} \mathrm{C}$. The starting weight loss of $31 \%$ shows that the decomposition of this complex begins with the loss of the maleic ligand. The complex with the hydroxylaminmaleate ligand shows less thermal stability, since the pyrolysis starts at $120^{\circ} \mathrm{C}$. The weight loss of $34 \%$ suggests the loss of hydroxylaminmaleic ligand [17].
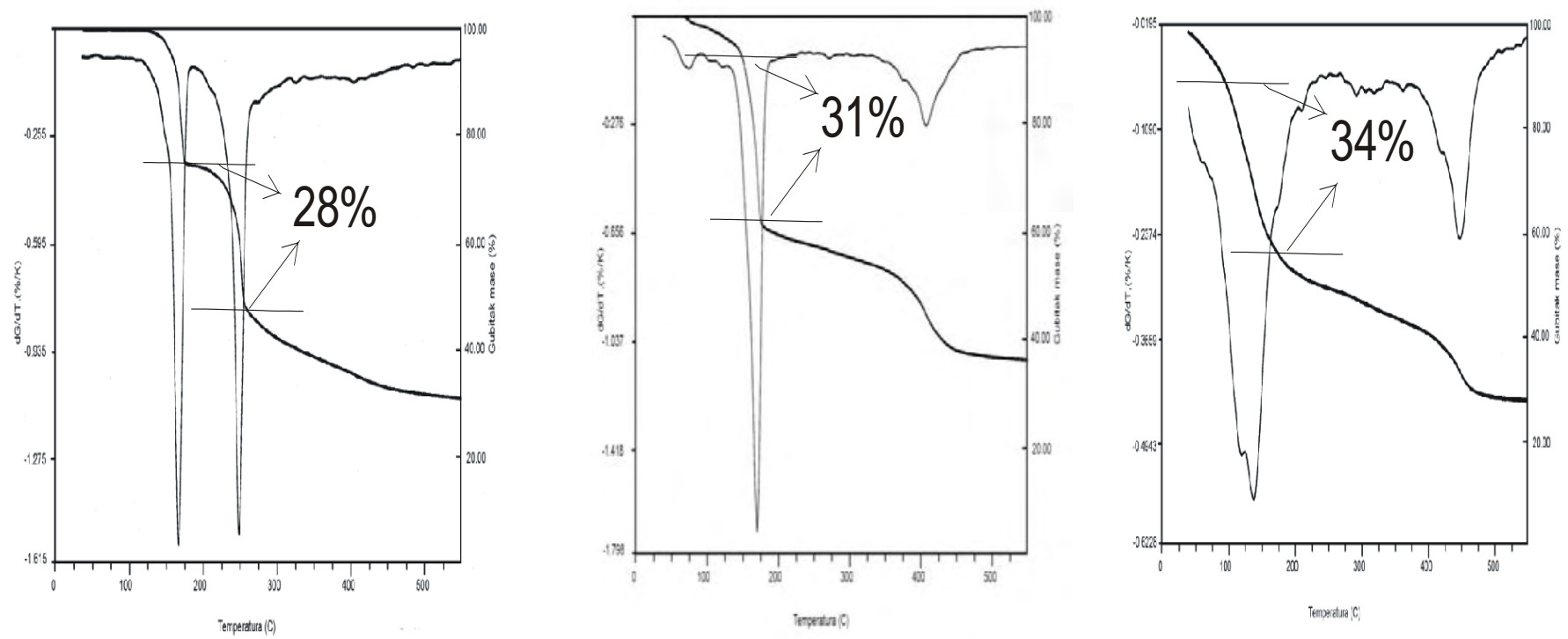

Figure 8. The TG and DTG curves

a) of $\mathrm{Mn}(\mathrm{III})$-acetylacetone,

b) of $\mathrm{Mn}(\mathrm{III})$-diacetylacetonemaleate and

c) of Mn(III)-diacetylacetonehydroxylaminmaleate.

\section{Conclusions}

The ligands of the maleic acid $\left(\mathrm{L}^{1}\right)$ and its hydroxylamine derivative $\left(\mathrm{L}^{2}\right)$, formed with the $\mathrm{Mn}(\mathrm{III})$ acetylacetone complex the mixed-ligand complexes of the general formula $\left[\mathrm{Mn}\left(\mathrm{C}_{5} \mathrm{H}_{7} \mathrm{O}_{2}\right)_{2} \mathrm{~L}\right]$. The complexes have been synthetized and characterized by means of the basic analyses, the magnetic susceptibility measurements, the IR and UV/VIS spectra. The replacement of the acetylacetone ligand by the corresponding acid ligand has been confirmed in Mn(III)-acetylacetone. Based on the obtained experimental data and the literature indications, the structural formulae have been assigned to these compounds.

The impact of the acid ligand on the $\mathrm{Mn}^{3+} / \mathrm{Mn}^{2+}$ balance, as well as the nature of the ligand itself, is the main factor in the selective catalysis of the aqueous two-component polyurethane formulations. 
The results obtained in this work could explain the lower hardness [12], and the reduction of the activation energy [18], of the formed films by using the Mn(III)-diacetylacetonehydroxylaminmaleate compared to the Mn(III)-diacetylacetonemaleate.

\section{Acknowledgements}

We gratefully acknowledge the financial support from the Ministry of Science, Technology and Development, Republic of Serbia (grant number ON 142039, BTN 351002.B and BTN 351004.B) for support of the work.

\section{References}

1. Noble, K.L. Waterborne polyurethanes. Progress in Organic Coatings 1997, 32, 131-136.

2. Collong, W.; Gobel, A.; Kleuser, B.; Lenhard, W.; Sootag M. 2K waterborne clearcoat-a competition between crosslinking and side reactions. Progress in Organic Coatings 2002, 45, $205-$ 209.

3. He, Z.A.; Blank, W.J.; Picci, M.E. A selective catalyst for two-component waterborne polyurethane coatings. Journal of Coatings Technology 2002, 74, 31-36.

4. Blank, W.J.; He, Z.A.; Hessell, E.T. Catalysis of the isocyanate-hydroxyl reaction by non-tin catalysts. Progress in Organic Coatings 1999, 35, 19-29.

5. Stamenkovic, J.; Cakic, S.; Nikolic, G. Study of the catalytic selectivity of an aqueous twocomponent polyurethane system by FTIR spectroscopy. Chem. Industry 2003, 57, 559-562.

6. Nikolaev, A.F.; Belogorodskaya, K.V.; Shibalovich, V.G.; Andreeva, E.D. Poluchenie i svoistva bisacetilacetonatokarboksilatov marganca III. Journal of Applied Chemistry 1973, 12, 2718-2725.

7. Diaz-Acosta, J.; Baker, J.F.; Pulay, P. Calculated and experimental geometries and infrared spectra of metal tris-acetylacetonates: vibrational spectroscopy as a probe of molecular structure for ionic complexes. Part II. Spectrochimica Acta Part A 2003, 59, 363-377.

8. Bruenner, R.; Obirth, A. On the mechanism of metal chelate catalysis in the reaction between alcohols and isocyanates. Journal Chem. Society 1965, 31, 887-891.

9. Shibalovich, V.G.; Belogorodskaya, K.V.; Karkozov, V.G. Novye kataliticheskie sistemy na osnove khelatnih komplesov marganca(III) i ikh primenenie $\mathrm{v}$ processakh polimerizacii i otverzhdeniya. Plast. massy 1989, 11, 18-25.

10. Ligabue, R.; Monteiro, A.; Souza, R.; Souza, M. Catalytic propertis of Fe(acac) $)_{3}$ and $\mathrm{Cu}(\mathrm{acac})_{2}$ in the formation of urethane from a diisocyanate derivative and EtOH. Journal of Molecular Catalysis A: Chemical 1998, 130, 101-105.

11. Stamenkovic, J.; Cakic, S.; Konstantinovic, S.; Stoilkovic, S. Catalysis of the isocyanate-hydroxyl reaction by non-tin catalysts in waterborne two-component polyurethane coatings. Facta Universitatis 2004, 2, 243-250.

12. Stamenkovic, J.; Cakic, S.; Stoilkovic, S. The influence of catalysts selectivity at physicalmechanical properties of two-component polyurethane coatings. World of Polymers 2003, 6, 257292. 
13. Nakamoto, K.; McCarthy, P.J.; Ruby, A.; Martell, A.E. Infrared Spectra of Metal Chelate Compounds. II. Infrared Spectra of Acetylacetonates of Trivalent Metals. Journal of American Chemical Society 1961, 83, 1066-1069.

14. Stults, B.R.; Marianelli, R.S.; Day, V.W. Distortions of the coordination polyhedron in high-spin manganese(III) complexes. I. Synthesis and characterization of a series of five- and six-coordinate bis(acetylacetonato)manganese(III) complexes. Crystal structure of azidobis(acetylacetonato)manganese(III). Inorganic Chemistry 1975, 14, 722-730.

15. Perina, G.N.; Shibalovich, V.G.; Nikolaev, A.F. Smeshchanno-ligandnye kompleksy marganca (III) na osnove trisacetilacetonata marganca i neorganicheskih kislot. Journal of Applied Chemistry 1982, 1, 30-37.

16. Josheska, N. The Study of acrilonitrile polymerization with water solution of sodium-rhodanide, iniciated by Mn(III) complex with mixed ligands. PhD Thesis, Faculty of Technology, University of Nis, Serbia, 1992.

17. DeVos, D.E.; Weckhuysen, B.M.; Bein, T. ESR Fine Structure of Manganese Ions in Zeolite A Detects Strong Variations of the Coordination Environment. Journal of American Chemical Society 1996, 118(40), 9615-9622.

18. Cakic, S.; Lacnjevac, C.; Rajkovic, M.B.; Raskovic, Lj.; Stamenkovic, J. Reticulation of Agueous Polyurethane Systems Controlled by DSC Method. Sensors 2006, 6, 536-545.

(C) 2006 by MDPI (http://www.mdpi.org). Reproduction is permitted for noncommercial purposes. 